\title{
Do Workers Who Experience Conflict between the Work and Family Domains Hit a “Glass Ceiling?” A Meta-Analytic Examination
}

\author{
Jenny M. Hoobler* \\ $\mathrm{Jia} \mathrm{Hu}$ \\ Morgan Wilson \\ Department of Managerial Studies \\ School of Business Administration \\ University of Illinois at Chicago \\ IL, United States
}

*Corresponding author. Department of Managerial Studies, School of Business

Administration, University of Illinois at Chicago, 2212 University Hall, MC 243, Chicago, IL 60607-7123, United States. Fax: +1 312996 3559. E-mail address: jhoobler@uic.edu. Acknowledgement The authors wish to thank Bob Liden and Hao Zhao for their helpful comments on an earlier version of this manuscript. 


\begin{abstract}
Based in Conservation of Resources (COR; Hobfoll, 1989) and self-verification (Swann, 1987) theories, we argue that when workers experience conflict between the work and family domains this should have implications for evaluations of their work performance, and ultimately affect more "objective" career outcomes such as salary and hierarchical level attained, as well as the attitudinal outcome of career satisfaction. Our meta-analysis of 96 studies, for a combined sample size of 32,783 , found that both work to family conflict (WFC) as well as family to work conflict (FWC) negatively impacted selfrated as well as manager-rated work performance. And our structural equation model found that WFC and FWC were negatively related to career satisfaction and hierarchical level attained. But while WFC was negatively related to salary, FWC was positively related to salary.
\end{abstract}

Key words: work-family, career, and work performance 
Do Workers Who Experience Conflict between the Work and Family Domains Hit a "Glass Ceiling?" A Meta-Analytic Examination

The term the glass ceiling was coined in the 1980's to characterize women and ethnic minorities' stifled career progress in organizations (Hymonitz \& Schellhardt, 1986). It signifies that invisible barriers truncate minority group members' achievement in organizations. Research has supported the existence of glass ceiling-type discrimination for many reasons including the prevalence of organizational cultures which place greater value on masculine, majority member characteristics and contributions (e.g., Acker, 1990; 1992), a lack of mentorship (e.g., Ragins \& Cotton, 1991), a lack of accumulated human capital (Fernandez, 1998), and ethnic discrimination (Foley, Kidder, \& Powell, 2002). The term the glass ceiling has traditionally been used to describe organizational career barriers for women and ethnic minorities. However, recent research has uncovered a glass ceiling effect for those workers who are perceived to have conflict between the family and work domains. Specifically, Hoobler, Wayne, and Lemmon (2009) found a "family-work conflict bias" such that when supervisors perceived their subordinates as higher in familywork conflict (FWC; perceptions that family roles—e.g., parent, eldercare-giver, spouse/partner - spill over to affect the fulfillment of work roles), supervisors perceived those subordinates to be lower performers, and the subordinates ultimately received fewer promotions - a new way of understanding the glass ceiling. In this study we use metaanalysis to bring the sum of existing research to bear on this question of whether there are glass ceiling career effects for all workers who experience conflict between the work and family domains. While the glass ceiling has traditionally referred to barriers to the 
corporate suite, our meta-analysis includes respondents from multiple hierarchical levels, taking a broader definition of the glass ceiling consistent with Hoobler and colleagues' (2009) conceptualization.

We propose that FWC and WFC (work-family conflict: the perception that work roles and family roles are incompatible in some respect, and participation in the family role is made more difficult due to spillover from work responsibilities - Greenhaus \& Beutell, 1985) are detrimental to a variety of career outcomes. Today's view of the "ideal worker" is one who is available to come in early, stay late, and drop everything for the company if necessary. What has been called the " $24 / 7$ economy," that is, our new technological/information society, has created a great deal of complexity and uncertainty for workers, and the integration of work and nonwork demands is one of the most critical challenges for organizations, families, and individuals today (Kossek \& Lambert, 2005). Empirical evidence is mounting that the boundaries between work life and family life are now blurred. "The behavioral and attitudinal norms of the workplace encroach on nonwork life and relationships, contributing to conflicts between the demands of work and family roles" (Hammer, Saksvik, Nytrø, Torvatn, \& Bayazit, 2004, p. 85). As Crooker, Smith, and Tabak (2002) relate, forces outside the individual such as work hours, schedule flexibility, on-call requirements, career changes, family demographics (e.g., number of children, elder care responsibilities), and varying degrees and types of social support contribute to individuals' sense of balance or imbalance between the work and home spheres.

Our study takes a necessary look at the accumulated empirical evidence to answer a simple yet important question: do conflicts between work and family affect workers' career progress? When workers cannot meet the expectations of today's jobs due to family 
responsibilities, and vice versa, we test whether this has implications for evaluations of their work performance, and ultimately affects more "objective" career outcomes such as salary and hierarchical level attained, as well as attitudinal outcomes such as career satisfaction. We contribute to theory building in this area by calling on Conservation of Resources (COR; Hobfoll, 1989) and self-verification (Swann, 1987) theories to underpin our hypotheses. Eby, Casper, Lockwood, Bordeaux, and Brinley (2005) have called for model testing, as we do in this study, to move the work and family literature toward new theorizing. Ninety-six studies and a combined sample size of 32,783 are utilized to test our hypotheses. Figure 1 shows our hypothesized model.

Insert Figure 1 about here

Theory and Hypotheses

Conflict between the Work and Family Domains and Work Performance

Work-family conflict and to a lesser extent family-work conflict, have been vigorous areas of research activity in recent decades. This is due to many factors including women's increased labor force participation and the preponderance of dual earner parenting, escalating employer interest in improving workers' quality of life and in smoothing the work-life balance, and the "24/7 economy's" blurring of work and family time (Eby et al., 2005). Greenhaus and Beutell's (1985) review specified three major sources of conflict between both domains: time-based conflict (e.g., a meeting runs late and a parent is tardy picking up a child from daycare), strain-based conflict (e.g., a morning fight with a spouse/partner affects the quality of a salesperson's presentation that day), and 
behavior-based conflict (e.g., where a supervisor's style of directing his factory workers is not appropriately applied to directing his wife on a home improvement project). To this typology, Ezzedeen and Swiercz (2007) recently added a fourth: cognitive-based workfamily conflict, for example, where, even when not at work, a person is often distracted by work-related thoughts and worries, which detracts from non-work relationships.

Some general research findings link work-family conflict to lower job and life satisfaction (Kossek \& Ozeki, 1998) and psychological distress (Burke \& Greenglass, 1999; Frone, Russell, \& Cooper, 1997). Family-work conflict has been shown to negatively affect work performance and many job attitudes (Kossek \& Ozeki, 1999), and to positively relate to mood, anxiety, and substance disorders (Frone, 2000). Further career and work consequences for WFC include turnover intentions (Greenhaus, Parasuraman, \& Collins, 2001), job stress (Netemeyer, Maxham, \& Pullig, 2005), lower career satisfaction (Martins, Eddleston, \& Veiga, 2002), and lower perceptions of career success (Peluchette, 1993). Work outcomes from FWC include job stress (Netemeyer et al., 2005), lower person-job and person-organization fit (the degree to which the skills and values of the person match the job's and the organization's) (Hoobler et al., 2009), and lower self-efficacy at work (Netemeyer, Boles, \& McMurrian, 1996).

Work Performance. Individual work performance is defined as the quality and quantity of work produced by a certain individual. Performance is a relatively common behavioral outcome examined in the work and family literature. And this relationship has been examined meta-analytically to gain an appreciation for the magnitude of the relationship across samples. Though hampered by the availability of few studies, metaanalytically, 1) Kossek and Ozeki (1999) found that both FWC and WFC were negatively 
related to work performance ( $\rho=-.03$ and -.45 , respectively), and 2) Gilboa, Shirom, Fried, and Cooper (2008) found that WFC negatively related to general work performance (a composite, calculated measure of work performance) $(\rho=-.12)$ and self-rated work performance ( $\rho=-.16)$, but that WFC did not significantly relate to supervisor-rated work performance. In Hoobler and colleagues' (2009) study, the relationship between familywork conflict and managers' work performance ratings was a key determinant in subordinates' advancement-i.e., the promotions subordinates received and their managers' assessments of their future promotability. We felt that parsing the effects of conflict on both self- and manager-reported work performance was important based on these earlier findings. In their study, there was a significant difference between the amount of FWC subordinates self-reported and the perceptions of their subordinates' FWC that supervisors reported. Female subordinates actually reported less FWC than did their male counterparts, but supervisors perceived that their female subordinates experienced higher FWC than did male subordinates. Important to our study, the more FWC supervisors perceived their subordinates experienced, the lower they rated their work performance. We contend that self-reported WFC and FWC will relate negatively to manager-rated work performance.

WFC and Work Performance. To date, most work and family research has been theoretically predicated on theories of scarcity (van Steenbergen, Ellemers, \& Mooijaart, 2007), as in Conservation of Resources (Hobfoll, 1989) theory-which states that the threat of or actual loss of resources creates stress, which affects energy and effort (Campbell, 1990). Important to the scarcity view is that individuals are assumed to have a fixed amount of time and human energy (Marks, 1977). WFC is associated with decreased work performance because the process of juggling both work and family and the accompanying 
anxiety and stress created means resources are lost, and optimal work performance is not possible (Grandey \& Cropanzano, 1999).

FWC and Work Performance. The relationship between FWC and work performance is also based theoretically on the idea of scarcity of resources (or COR). As resources (e.g., time and energy) become scarce as workers enact both work and family roles, workers withhold effort in order to conserve personal resources in one domain or both, and, this should result in a decrease in others' assessments of their work performance (e.g., being less cooperative, cutting corners, and forgoing opportunities to improve their skills). This may be an intentional process, as Witt and Carlson (2006) explain: "time pressures, strain, and behavioral constraints caused by FWC decrease [employees'] motivation to expend and maintain high levels of effort at work" (p. 344), or may be the unintended result of simply having fewer resources to bring to bear on performance of the job.

Hypothesis 1: Self-reported WFC (1a) and FWC (1b) are negatively associated with manager-reported work performance.

The absence of the self has been levied as a criticism of theorizing in work and family research (Parker \& Hall, 1992; Eby et al., 2005). That is, how do people make sense of how they balance both work and family, and what do these choices say about who they are and their perceived success as a worker, a parent, a caregiver? We assert that the self, embedded in larger contemporary psychosocial norms, is important in understanding the outcomes of conflict between work and family. Based in self-verification theory, we contend that workers judge themselves against standards for family care that are structurally incompatible with standards for the "ideal worker." As far as the ideal worker, 
Quick, Henley, and Quick (2004) write of "self-imposed demands" for excessive work involvement that originate partially from personality (Type A, workaholism), but demands that are also externally facilitated by the era of work-anywhere laptop computers, mobile phones, and email. The drive to be in communication with work contacts at all times is made more difficult in combination with family responsibilities.

The changing nature of work in knowledge economies has blurred the boundaries between work time and family time. Over just the past decade, technology has enabled workers to do work anytime and anywhere, the hours we work have risen (Ng \& Feldman, 2008), and pressures to work faster and more productively have increased (Milliken \& Dunn-Jensen, 2005). Yet, these external pressures do not alone create a sense of imbalance nor are they alone responsible for feelings of psychological discomfort. Research is accumulating that suggests that psychosocial norms regarding work and family expectations play an additional, key part in determining the standards to which individuals hold themselves, and the outcomes that result under conditions of imbalance (Hammer et al., 2004). Crooker and scholars (2002) present the case of Baby Boomers (those born from circa 1946 to 1964) who are facing elder care responsibilities (Bond, Galinksy, \& Swanberg, 1998). A prominent norm is that a good child takes care of his or her parents, and some adult children may enact this by keeping their elderly parent at home, a choice that may involve the trade-off of providing sub-par work performance in a certain, demanding career. This dilemma about elder care, careers, and money is a personal one, with little external pressure. As Joan Williams (Smith, 2001) has stated, both men and women in this country feel trapped between two ideals. We want to define ourselves as a responsible, committed worker, and also as a responsible, committed parent or family 
member. But in our own minds we feel these two ideals are at odds with one another. Individuals foster conflicting beliefs involving these issues, with little possibility of satisfying all desires.

Based in self-verification theory, we suggest that both WFC and FWC are related to negative self-views of work performance. Gilboa and colleagues (2008) have recently documented the negative association of WFC with self-rated work performance via metaanalysis, yet we believe the association between FWC and self-rated work performance remains untested via meta-analytic methods (but supported in many individual studies, e.g., Frone et al., 1997; Karatepe \& Kilic, 2007; van Steenbergen et al., 2007). Self-verification theory explains the relationship between self-rated conflict and self-rated work performance. This theory emphasizes the importance of congruence between an individual's perception of themselves and important others' perceptions (e.g., the boss or well-respected members of the work group) (Swann, 1987). Failing to verify a desired selfconcept (here, ideal worker in the face of family member responsibilities or vice versa), as Swann (1987) states, has psychologically “painful consequences” (p. 1039), resulting sometimes in the formation of new, different, and verifiable identities. Thatcher and Zhu (2006) posit that successful identity verification leads to higher work performance. We suggest that, whether it be family conflicting with work demands or work conflicting with family demands, either type of imbalance means that workers' view of themselves as failing to reach standards for the "ideal" will be associated with harsh judgments of their own work performance. For example, when workers encumbered with family duties evaluate their work performance in the era of "availability at all times," this incongruence or lack of self-verification is likely to be associated with lower work performance. Self- 
verification theory predicts that people who have adopted negative self-views (i.e., "not an ideal worker") not only prefer and seek out negative feedback (Swann, Pelham, \& Krull, 1987) but also act in ways designed to illicit negative feedback and dismiss positive reactions as inaccurate (Swann, Griffin, Predmore, \& Gaines, 1987).

Hypothesis 2: Self-reported WFC (2a) and FWC (2b) are negatively associated with self-reported work performance.

While we have predicted in both Hypotheses 1 and 2 a negative relationship between both WFC and FWC and work performance, inherent to these hypotheses is that the source of the work performance rating (manager/supervisor versus self) moderates the strength of this negative relationship. Based in scarcity of resources theories, managers' assessments of the actual work performance of their subordinates are likely to be negative when the juggling act between work and family means less resources are available to apply to work performance (Hypothesis 1). On the other hand, our arguments in Hypothesis 2 above about self-reports of work performance were underpinned by self-verification theory - the idea that self-assessments of performance are filtered through society's archetype of the ideal worker and parent. Comparatively, we hypothesize that because managers' assessments are the closer approximation of "true" performance, that is, managers have been found to show less leniency in performance ratings as compared to the self (Heidemeier \& Moser, 2009), managers' ratings should more strongly impact the relationship between conflict and work performance. Self-perceptions of performance visà-vis self-verification theory are important and they may also qualify the relationship between conflict and work performance, but they are strongly impacted by other external/societal factors. Hence we suggest that managers' performance assessments will 
more strongly moderate, that is, strengthen the negative association between WFC/FWC and work performance.

Hypothesis 3: The source of the work performance rating (manager versus self) moderates the relationship between self-reported WFC (3a) and FWC (3b) and work performance, such that the relationship is more strongly negative when work performance ratings are manager-reported than when they are self-reported.

\section{A Model of the Combined Effects of WFC and FWC on Career Outcomes}

In an effort to move beyond just the commonly-studied behavioral outcome of work performance, and to test our ideas of the "glass ceiling" career effects of WFC and FWC, we created a theoretical model (illustrated in Figure 1) that is designed to explain: 1) the impact of work performance (both manager- and self-reports combined; see Method section for an explanation), 2) “objective” outcomes, specifically salary and hierarchical level attained, and 3) a relatively common attitudinal career outcome-career satisfaction. Based in the scarcity (COR) arguments advanced above, when workers' resources are constrained in the juggling act of conflict between work and family, this leaves fewer resources such as effort, energy, and affect available to do the job. We suggest that this lack of resources manifests in objective, specific outcomes — salary and hierarchical level attained — as well as workers' summative attitude toward their career-career satisfaction (Martins et al., 2002; Parasuraman \& Simmers, 2001). This set of outcomes is consistent with research on careers that suggests that career success is an integration of objective achievements such as salary and hierarchical level attained, and subjective evaluations such as career satisfaction (Wayne, Liden, Kraimer, \& Graf, 1999; Seibert, Kraimer, \& Liden, 2001). Workers who experience conflict between the home and work are likely to apply resources to handle or 
correct the conflict, resulting in fewer resources such as passion, cognitive focus, and vigor available to apply to one's job. As a result, managers' assessments of their subordinates' career outcomes will be negatively impacted.

Additionally, as workers find themselves with scarce resources their perceptions of their own career satisfaction will be negatively impacted. The relationship between WFC and career dissatisfaction has been well documented in the literature (e.g., Martins, Eddleston, \& Veiga, 2002), and is based on the scarcity of resources idea. Juggling responsibilities in both domains leaves less time, energy, and the like to achieve the satisfaction of "a job well done," i.e., career satisfaction. The relationship between FWC and career satisfaction is predicated on a combination of both COR and self-verification theories. Workers experiencing FWC will consider their family to be the source of depleted resources for work tasks, assess themselves as failing to meet expectations for the "ideal" worker, and will self-verify this low assessment in reports of lower satisfaction with their career.

Hypothesis 4: Self-reported WFC is negatively associated with salary (4a), hierarchical level attained (4b), and career satisfaction (4c).

Hypothesis 5: Self-reported FWC is negatively associated with salary (5a), hierarchical level attained (5b), and career satisfaction (5c).

One specific mechanism through which WFC and FWC may impact salary and hierarchical level attained is work performance assessments (Cadsby, Song, \& Tapon, 2007). That is, perceptions of low work performance are likely to explain the effect of WFC and FWC on these career outcomes. According to COR theory, when pressures from work or family reduce the amount of resources available to expend in either domain, 
workers will act in ways to prevent further loss of personal resources (Hobfoll, 2001). Workers withhold effort to preserve existing resources, and therefore may experience a decrease in work performance as a result (Witt \& Carlson, 2006). We suggest that this decrease in work performance will not go unnoticed in the organization, manifesting itself as lower salary and fewer promotions (Hoobler et al., 2009), that is, lower hierarchical level attained. Our hypotheses are stated as partial mediation as we also expect direct relationships between WFC/FWC and the objective career outcomes, as hypothesized in $\mathrm{H} 4$ and 5 above. Moreover, there may be other factors that we were unable to test metaanalytically that mediate these relationships besides work performance.

Hypothesis 6: Work performance partially mediates the relationship between WFC and salary (6a) and hierarchical level attained (6b).

Hypothesis 7: Work performance partially mediates the relationship between FWC and salary (7a) and hierarchical level attained (7b).

We do not hypothesize direct relationships between work performance, salary, hierarchical level attained, and career satisfaction, as these have been illustrated in other studies (e.g., Abele \& Spurk, 2009; Beutell, \& Wittig-Berman, 1999; Ng, Eby, Sorensen, \& Feldman, 2005).

\section{Method}

\section{Literature Search}

In order to identify all possible studies that explored the relationships between WFC/FWC and our career outcomes (work performance, salary, hierarchical level attained, career satisfaction), we conducted an online search of both the PsycInfo and the ABI/Inform database for published studies up until November 2009. We conducted 
searches with "work-family conflict" together with work performance and each of the career outcomes as well as searches with "family-work conflict" together with work performance and each of the career outcomes. We also conducted searches with "family" together with work performance and each of the career outcomes as well as "work family" and each of the outcomes to identify any other articles that may fit our frame of interest. Further, we sent an email to the Academy of Management Organizational Behavior and Human Resource Management listservs requesting any unpublished/in press papers, unpublished data, conference presentations or dissertations that would be appropriate for our study. We entered the search results into RefWorks (a reference management program) in order to identify and remove any duplicate papers. The search resulted in 751 studies through this process. Next, we screened the articles to eliminate any articles that were purely theoretical or practitioner-oriented. We also eliminated any articles that did not contain means and standard deviations of the variables of interest, as this data is required for meta-analysis. This initial screening process resulted in 148 studies.

In order to be included in the meta-analysis, a study had to meet certain criteria. First, the study had to include work-family conflict or family-work conflict measured as an overall construct, rather than reporting correlations with subscales of WFC or FWC. We focused on overall measures of WFC or FWC because the overall measure most closely represented our research interests. Secondly, the study had to include a Pearson correlation coefficient between WFC or FWC and at least one of the career outcome variables of interest (i.e., work performance, salary, hierarchical level attained, and career satisfaction). Hierarchical level attained was a categorical variable that measured respondents' level achieved in the organization (i.e., nonmanagement, nonsupervisory, management, upper 
management, etc.). After eliminating studies that did not meet these criteria, a total of 90 studies remained. Six of these papers included multiple samples, resulting in a total of 96 usable samples for the meta-analysis. These 96 studies have a combined sample size of 32,783. A subsample size of 10,861 from 37 studies was used in our hypothesis testing, with the remaining 56 studies required for correlations that were not hypothesized, but were necessary to complete the full correlation matrix necessary to use SEM (e.g., studies with correlations between WFC and FWC). Three papers used in our hypothesis testing included more than one effect size. The final list of studies is available from the authors.

Additionally, we conducted a separate search for studies with reported correlations between age and our variables of interest, so we could control for age in our structural equation model. We controlled for age in our analyses because previous researchers have found that age has a significant impact on career progress (Goldberg, Finkelstein, Perry, \& Konrad, 2004), and it could be argued that salary and hierarchical level are predominantly a function of age. We sought to partial out the variance in the relationships between WFC, FWC and salary and hierarchical level that was due strictly to a respondent's age. In conducting literature searches for these relationships, we found existing meta-analyses that reported the correlation between age and 1) career satisfaction, 2) salary ( $\mathrm{Ng}$, Eby, \& Sorensen, 2005) and 3) work performance (McEvoy \& Cascio, 1989). We conducted our own searches for the remaining correlations between age and the other variables in our model. Our model does not control for many family demographic factors such as number of children and use of daycare facilities that are often included as controls in work and family research; we believe these factors are more likely exogenous to our model, 
contributing more to self-perceptions of WFC and FWC than to the relationship between WFC/FWC and career outcomes.

Included studies were coded by two of the authors independently in order to ensure accuracy. The intercoder agreement was 90\%. Any discrepancies were solved by discussions between the authors, by consensus. If any papers reported multiple studies within the paper (i.e., multiple independent samples), the studies were coded as separate studies and entered into the meta-analysis as independent samples, per Hunter and Schmidt's (2004) recommendation.

\section{Statistical Procedures}

We adopted Hunter and Schmidt's (2004) method of meta-analysis to test our hypotheses. As such, correlation coefficients were the effect sizes of interest. We first corrected for measurement error. We corrected each individual correlation for unreliability in the measurement using the alpha values $(\alpha)$ reported in the study. In the few cases where no alpha value was reported for a particular scale, we calculated an alpha value for that scale by using the mean from the rest of studies. We then used the individual corrected correlation to calculate the overall sample-weighted correlation, correcting for sample error. These corrected correlations were then used to test our hypotheses using structural equation modeling (SEM).

Besides the corrected correlations, we also report several other statistics for metaanalysis, which can be found in Table 1 . We report the $95 \%$ confidence interval as well as the $80 \%$ credibility interval. The confidence interval is an interval estimate of a population parameter, used to indicate the reliability of the estimate. The confidence interval determines the probable amount of error in the corrected correlation due to sampling error 
(Hunter \& Schmidt, 2004, p.205). The credibility interval, on the other hand, is based on $\mathrm{SD}_{\mathrm{p}}$ (the standard deviation based on the corrected correlation) and refers to the distribution of parameter values. Credibility intervals can be used to provide information as to whether moderators are likely present. We also report two $\mathrm{Q}$ statistics: $\mathrm{Q}_{\mathrm{w}}$ and $\mathrm{Q}_{\mathrm{b}}$. $\mathrm{Q}_{\mathrm{w}}$ is a homogeneity statistic that tests within-class effects and a nonsignificant $\mathrm{Q}_{\mathrm{w}}$ reflects homogeneity within-class. $\mathrm{Q}_{b}$ is a heterogeneity statistic that tests between-class effects and a significant $\mathrm{Q}_{\mathrm{b}}$ indicates considerable heterogeneity in the effect sizes across studies (Lipsey \& Wilson, 2001). The last statistic we report is the fail-safe $k$. This statistic is used to acknowledge the "file drawer problem," which is the exclusion of papers that did not produce significant results being literally and figuratively in authors' file drawers (and therefore not published). The fail-safe $k$ is a statistic that aims to calculate the number of non-significant studies that, if in existence, would be necessary to reduce the effect size to a non-significant value (Hunter $\&$ Schmidt, 2004). As the value of the fail-safe $k$ increases, the results are less likely to change due to missing studies.

Insert Table 1 about here

\section{SEM Analysis Technique}

To determine how WFC and FWC influence career progress, we conducted a path analysis using a SEM approach and the LISREL 8.72 software (Joreskog \& Sorbom, 1993). Integrating SEM with a meta-analytically generated matrix is considered a useful way for theory testing (e.g., Colquitt, Scott, \& LePine, 2007; Zhao, Wayne, Glibkowski, \& Bravo, 2007). To use a meta-analysis correlation matrix as the input for SEM, we needed to 
supplement twelve correlations that were not available from our study (Viswesvaran \& Ones, 1995). We thus filled the twelve missing cells by both conducting separate metaanalyses to gain six correlations and also by referring to three published meta-analyses to retrieve the other six correlations between variables. The notes in Table 2 delineate the source of each effect size.

Insert Table 2 about here

Because sample sizes were different across the cells in the matrix, we used the harmonic mean of sample sizes as the sample size for the LISREL modeling. According to Viswesvaran and Ones (1995), the harmonic mean can result in more conservative estimates and reflect the true mathematical accuracy of the analysis. We interpreted goodness of fit using CFI, NFI, GFI, RMSEA, and SRMR, and we used commonly recommended cutoff values as indicators of good fit $(\mathrm{CFI}>.90, \mathrm{NFI}>.90, \mathrm{GFI}>.90$, RMSEA < .08, and SRMR < .06) (e.g., Hu \& Bentler, 1999). In the structural models, we combined manager-rated work performance and self-reported work performance to indicate multiple sources of work performance assessments. In the path analysis, paths from the latent variables to observed variables were calculated by the square root of the reliability of the corresponding measure, and the error variance of the latent variable was determined by one minus the reliability of the measure times the variance of the measure (Cortina, Chen, \& Dunlap, 2001). Reliability of the single-item measures (e.g., salary, hierarchical level attained, control variable age) was set to be .90 (e.g., Dulac, Coyle-Shapiro, Henderson, \& Wayne, 2008). With respect to the mediation predictions in Hypotheses 6 and 7, we 
calculated the indirect effect and tested the significance of an indirect effect by dividing the estimate of the indirect effect by its standard error estimate (Sobel, 1982).

In our model test we chose to combine manager- and self-reports of work performance for two reasons. First, based on Hypothesis 3, we predicted that while there may be differences of magnitude in the association between WFC/FWC and work performance based on the source of work performance ratings, all relationships are predicted to be negative. Second, an examination of our meta-analytic corrected correlations revealed that the signs on the relationships between both sources of reports of WFC and FWC and all variables in our model were in the same direction (all either negatively or positively related). Hence we proceeded by creating one measure of work performance across both sources of ratings for use in our SEM.

\section{Results}

\section{WFC/FWC and Work performance}

Table 1 provides a summary of the correlations between WFC, FWC, and the other three career-related outcomes: salary, hierarchical level attained, and career satisfaction. As shown in Table 1, WFC was related to both salary and hierarchical level attained in a positive as opposed to the hypothesized negative direction ( $\rho=.13, \mathrm{CI}=.05, .17$ for salary; $\rho=.13, \mathrm{CI}=.04, .18$ for hierarchical level attained) but was negatively related to career satisfaction as predicted ( $\rho=-.11, \mathrm{CI}=-.21,-.01)$. FWC was negatively related to salary $(\rho=-.08, \mathrm{CI}=-.10,-.04)$ and career satisfaction $(\rho=-.22, \mathrm{CI}=-.23,-.21)$, but positively related to hierarchical level attained $(\rho=.11, \mathrm{CI}=.07, .13)$.

Hypothesis 1 predicted that WFC (1a) and FWC (1b) would be negatively related to manager-rated work performance. The meta-analysis results showed that both WFC and 
FWC were significantly negatively related to manager-rated work performance ( $\rho=-.19$ for WFC, and $\rho=-.16$ for FWC). The 95\% confidence intervals for both effect sizes excluded zero, indicating that the corrected correlations were significantly different from zero at the $p<.05$ level. The $80 \%$ credibility interval was wide and excluded zero for both correlations, suggesting considerable variability of the corrected correlations across studies. In addition, the relatively large fail-safe $k$ (61 and 86 respectively) means that at least 61 (for WFC-manager-rated work performance) and 86 (for FWC-manager-rated work performance) file-drawer studies with an overall null effect are needed to drop the estimated effect sizes to less than a significant level. Therefore, Hypotheses 1a and $1 \mathrm{~b}$ were supported.

Hypothesis 2 posited that WFC (2a) and FWC (2b) would negatively relate to selfreported work performance. The meta-analysis results evidenced this ( $\rho=-.03$ for WFC; $\rho=-.22$ for FWC). The $95 \%$ confidence intervals excluded zero for both of these relationships, and fail safe $k$ was relatively large, indicating support for Hypotheses $2 \mathrm{a}$ and $2 b$.

To test for the moderating effect of the source of the work performance rating (manager versus self) on the relationships between WFC/FWC and work performance (Hypothesis 3a and 3b), we first examined the significance of the $\mathrm{Q}_{\mathrm{b}}$ statistic. Supporting our prediction, as shown in Table 1, the $\mathrm{Q}_{\mathrm{b}}$ statistics for the relationships between both WFC and FWC and work performance were significant: $\mathrm{Q}_{\mathrm{b}}=44.78, p<.001$ for WFC, and $\mathrm{Q}_{\mathrm{b}}=39.74, p<.001$ for FWC. The relationship between WFC and work performance was stronger when work performance was rated by managers $(\rho=-.19)$ than when it was selfrated ( $\rho=-.03$ ), supporting Hypothesis 3a. However, contrary to Hypothesis $3 \mathrm{~b}$, the 
relationship between FWC and work performance was stronger for self-rated work performance $(\rho=-.22)$ than for manager-rated work performance $(\rho=-.16)$. SEM Analyses for the Influence of WFC and FWC on Career Outcomes

To test the influence of WFC and FWC on a variety of career outcomes as specified in Hypotheses 4 through 7, we tested our model using SEM path analysis. As shown in Figure 1, our hypothesized model included direct paths from both WFC and FWC to work performance, salary, hierarchical level attained, and career satisfaction. Also included were paths from work performance to salary and hierarchical level attained, and salary and hierarchical level attained to career satisfaction.

Figure 2 presents the path estimates of our hypothesized model. The effects of age on salary and hierarchical level attained were controlled in the model because as workers age, their experience usually increases, raising their earning power and hierarchical position; as well, family responsibilities tend to increase with age. To rule out that our findings with respect to salary and hierarchical level were not due simply to respondents' age, but rather to the work and family conflict, we partialed out the variance due to age. With respect to the hypotheses, Hypothesis 4 predicted that WFC would be negatively related to salary (4a), hierarchical level attained (4b), and career satisfaction (4c). The path analysis results supported just the effect of WFC on career satisfaction: WFC was shown to be negatively related to career satisfaction $(\beta=-.43, p<.001)$, providing support for Hypothesis 4c. However, WFC was positively as opposed to negatively related to salary $(\beta$ $=.43, p<.01)$ and hierarchical level attained $(\beta=.19, p<.01)$, failing to support Hypotheses $4 \mathrm{a}$ and $4 \mathrm{~b}$. 


\section{Insert Figure 2 about here}

Hypothesis 5 indicated that FWC would be negatively related to salary (5a), hierarchical level attained (5b), and career satisfaction (5c). This was supported for the effect of FWC on salary $(\beta=-.39, p<.01)$ and career satisfaction $(\beta=-.51, p<.001)$, but not for the effect of FWC on hierarchical level attained. Therefore, Hypotheses 5a and 5c were supported, but Hypothesis 5b was not.

Hypothesis 6 was confirmed in that work performance partially mediated the relationship between WFC and salary (6a) and hierarchical level attained (6b). As shown in Figure 2, work performance was significantly related to salary $(\beta=.29, p<.01)$ and hierarchical level attained $(\beta=.20, p<.05)$. The indirect effect of WFC on salary through work performance was significant $(\beta=-.14, p<.05)$. And the indirect effect of WFC on hierarchical level attained via work performance was significant $(\beta=-.10, p<.05)$. As described in Hypothesis 4, because WFC was significantly related to salary and hierarchical level attained, work performance partially mediated relationships between WFC and salary and hierarchical level attained.

Supporting Hypothesis 7, work performance partially mediated the relationship between FWC and salary (7a) and the relationship between FWC and hierarchical level attained (7b). The indirect effects of FWC on work performance for salary $(\beta=-.09, p<$ $.05)$ and hierarchical level attained $(\beta=-.07, p<.05$, one-tail test $)$ were significant, lending support for Hypotheses $7 \mathrm{a}$ and $7 \mathrm{~b}$.

Alternative Model Tests. As Williams, Bozdogan, and Aiman-Smith (1996) note, researchers who use SEM fail to disconfirm a model more than they actually confirm the 
model that they are testing. Thus, we compared the hypothesized partial mediation model with several alternative models. Although we hypothesized that both WFC and FWC would be related to career outcomes, we expected we might find that the influence of WFC and FWC on career outcomes was fully reliant on the role of work performance. This is because work performance is seen as a proximal determinant of career-related outcomes such as salary and hierarchical level attained (e.g., Cadsby et al., 2007). Hence, the hypothesized partial mediation model was compared to a series of similar, nested models: a null model, with none of the variables correlated; a direct-effects model (Model 1) with WFC and FWC relating to all career-related outcomes and no mediation; a full mediation model (Model 2) where the effects of WFC and FWC on career satisfaction are fully mediated via work performance, salary and hierarchical level attained (with the paths from WFC and FWC to salary, hierarchical level attained, and career satisfaction removed from the hypothesized model and other paths remaining); Model 3 containing paths from WFC and FWC to salary and hierarchical level, salary and hierarchical level to work performance, and work performance to career satisfaction (Does salary determine work performance?); and Model 4 involving paths from salary and hierarchical level to WFC and FWC, WFC and FWC to work performance, and work performance to career satisfaction (Is a higher salary and a job with more power related to more perceived conflict?). As shown in Table 3, our hypothesized partial mediation model produced a significantly better fit than the five alternative models: $\chi^{2}(4)=18.80, p<.001, \mathrm{GFI}=.99, \mathrm{NFI}=.99, \mathrm{CFI}=.99, \mathrm{RMSEA}=.05$, $\mathrm{SRMR}=.01$ 


\section{Discussion}

Through meta-analysis of existing research, we found support for the idea that those who experience conflict between the work and family domains experience glass ceiling-like career effects, basing our hypotheses on Conservation of Resources (COR) and selfverification theories. This meta-analysis joins others that have explored the WFC/FWC domain and adds to our understanding of these domains from a careers perspective. Building on Byron's (2005) meta-analysis, we moved beyond antecedents of conflict to focus on meta-analytic outcomes. Ford, Heinen, and Langkamer (2007) found that WFC and FWC served as mediators of the relationship between work (e.g., job stress) and family (e.g., family support) domain-specific variables and job and family satisfaction. We built on the foundation of both of these meta-analyses by exploring how WFC and FWC impact career outcomes, and moving beyond the commonly-explored outcomes of job satisfaction, life satisfaction and family satisfaction (e.g., Ford et al., 2007; Michel, Mitchelson, Kotrba, LeBreton, \& Baltes, 2009). While Gilboa and colleagues (2008) found that WFC was negatively related to a general measure of work performance and self-rated work performance, they did not find that WFC was significantly related to supervisor-rated work performance, as our results did suggest. A possible explanation for these incongruent metaanalytic findings could lie in the different methods employed. While Gilboa and colleagues (2008) used the Viswesvaran method (Viswesvaran, Ones, \& Schmidt, 1996) for correcting the measurement error of work performance, we employed the Hunter and Schmidt (2004) method, using the internal consistency estimates provided in each article. Gilboa and colleagues (2008) used the meta-analytic estimate of interrater reliability of supervisor 
ratings (.52) when making their corrections (Viswesvaran et al., 1996), which could have contributed to their non-significant finding for the relationship between WFC and supervisor-rated work performance.

Our first set of hypotheses contended that both WFC and FWC were negatively related to managers' reports of their subordinates' work performance, and our second set hypothesized that both WFC and FWC were negatively related to workers' self-reports of their work performance, and using meta-analysis techniques, we found support for these. Despite the source evaluating work performance, it seems that WFC and FWC both are negatively associated with work performance. When subordinates' cross-domain resources are scarce, managers seem to associate this with lower work performance, and when subordinates feel that they are doing a poor job of balancing work and family roles they will correspondingly evaluate their own work performance more negatively.

Results of Hypothesis 3 showed that the relationships between both WFC and FWC and work performance differ in terms of rater. Specifically, WFC was more negatively related to employee work performance when work performance was rated by the manager than when it was self-rated. What has been called the self-serving bias (Epley \& Dunning, 2000; Goerke, Moller, Schulz-Hardt, Napiersky, \& Frey, 2004) may be helpful in understanding this finding. While employees will rate their own work performance as negative when WFC colors their self-views, their tendency to judge themselves harshly may still be tempered in comparison with the tendency to harshly sanction others (as in the case of managers judging subordinates' work performance). However, in direct opposition to this line of thinking and inconsistent with Hypothesis 3, we found that the relationship between FWC and work performance was more negative for self-reported work 
performance than for manager-rated. Conflict from family to work more severely impaired employees' self-views of their work performance to the extent that they rated their performance lower than their managers did. While future research in this area is needed to understand the mechanism behind this, we refer to the social pressures of the 24/7 economy to interpret the meaning behind this result. That is, it could be that workers clearly understand the ideal worker as someone who is unencumbered by family commitments, so when family does interfere with work, they experience a great deal of psychological discontent — to the extent that they are harder on their own self-evaluations than even their bosses appear to be.

Our next hypotheses (4-6) pertained to our model of WFC and FWC's effects on multiple career outcomes. In creating this model, rather than testing a series of separate hypotheses, we believe we have answered Eby and colleagues' (2005) call for more model development (not just tests of single relationships) in the work and family literature. First, we contended that WFC and FWC are negatively associated with salary, hierarchical level attained, and career satisfaction. When workers experienced WFC and FWC they were less satisfied with their career, but only FWC was negatively related to salary (H5a); WFC was actually positively related to salary (H4a). And both WFC and FWC were positively related to hierarchical level attained, even after controlling for the effects of age on hierarchical level, which could have been a potential "third variable" explaining both the existence of family responsibilities and organizational hierarchical position. In trying to understand these findings that run counter to scarcity theories, we offer that these relationships between WFC and salary and hierarchical level attained actually make sense given our earlier arguments about the contemporary demands of the knowledge economy. 
One way of looking at this is that workers reap organizational rewards (salary and position) for putting their work before their family responsibilities. Putting the job first may result in supervisors noting and rewarding individuals' effort and choice to prioritize work over family, which over time means higher salary and more promotions. Future research may benefit from directly assessing managers' perceptions of subordinates' effort or commitment as possible mediators between WFC/FWC and objective career outcomes. However, we acknowledge, the small but positive relationship between FWC and hierarchical level attained would run counter to this same logic. Also interesting was that while WFC was associated with higher salary and hierarchical level, it was also associated with lower career satisfaction (the relationship between WFC and career satisfaction being even stronger than the relationship between FWC and career satisfaction). So while there may be organizational rewards for putting work first, workers do not seem pleased to do so. Similarly, while WFC seems to bring with it organizational rewards, it is also associated with lower performance. Workers may be putting the job first, but that does not seem to imply that they are working more effectively.

Second, we found that work performance mediated the relationship between WFC/FWC and salary (H6a, H7a) and hierarchical level attained (H6b, H7b). As our alternative model tests confirmed, both relationships represented partial mediation. That is, even with work performance as an explanatory variable in the model, WFC and FWC still have unique, direct effects on salary and hierarchical level attained, leading us to believe other potential mediators may exist as well, for example, job stress or absenteeism. For instance, when family interferes with work, it may increase absenteeism, which in turn may negatively impact employee salary. As an anonymous reviewer pointed out, the magnitude 
of the direct effect of WFC on salary $(\beta=.43, p<.01)$ was stronger than the indirect effect of WFC on salary through work performance $(\beta=-.14, p<.05)$. Furthermore, the total effect of WFC on salary would be the sum of the direct and indirect effects, .29. This value indicates that the positive effect of WFC on salary becomes weaker partially due to the mediation of work performance. We believe that the puzzle of how WFC influences salary may be resolved by exploring other potential mediators in future research.

We did not hypothesize relationships between work performance, salary, hierarchical level attained, and career satisfaction, because these relationships have been documented elsewhere and because the impact of $W F C$ and $F W C$ on career was our specific focus. However, worthy of mention is the finding that, in our SEM, salary was positively related to career satisfaction, but hierarchical level attained was negatively related to career satisfaction. Could it be that more money makes you happier in your career, but that job titles reflecting increased responsibility make you less so? In trying to understand these contradictory findings, we went back to the individual studies from which we calculated the corrected correlation between hierarchical level attained and career satisfaction. Our corrected correlation was based on only three studies that examined this relationship (see Limitations below). Due to its relatively larger sample size, one of these study's (Burke, 2001) influence on the sample-weighted correlation may explain the negative sign on the relationship between hierarchical level attained and career satisfaction in our model. We suggest that more studies are necessary to provide confidence in the negative association between these two career outcomes. 
While not without limitations, our study does have at least three strengths that should be noted. First, our model incorporates both WFC and FWC in the same model, acknowledging the fact that workers' conflict between the home and family sphere is not necessarily uni-directional. More realistically, over shorter time periods (e.g., seasonal or even project-by-project workload fluctuations) and over longer time periods (e.g., when children are age zero to three), workers can experience bi-directional conflicts between work and family. A more holistic picture of the impact of work and family on career is one that acknowledges the combined influence of both WFC and FWC. As well, our model confirms earlier research that finds there are asymmetric outcomes of both WFC and FWC (Burke \& Greenglass, 1999; Frye \& Breaugh, 2004). Second, our model of the impact of work and family on career was supported even when we controlled for age. A significant part of an individual's salary and the hierarchical level they have achieved is merely because older individuals have been in the workforce longer. We wanted to ensure that the association between family responsibilities and these career achievements was not simply due to a third variable - age. Third, we believe that the major strength of this manuscript lies in our statistical technique. By bringing the full weight of the accumulated research to bear on the question of whether conflict between the work and family domains is associated with glass ceiling-like career effects, we have controlled much sampling variability and many extraneous factors and have come closer to providing "evidence-based" knowledge.

As far as limitations of this study, we acknowledge that many more career outcomes of WFC and FWC potentially exist. The work and family literature has identified a great number of career outcomes, but many fall into the category of general attitudes, for example, job satisfaction, affective commitment, and to a lesser extent mood and behaviors. 
While general attitudes are interesting, many of their relationships with WFC and FWC have been examined elsewhere via meta-analysis, and our model focused more on outcomes directly related to career. Including additional "objective" outcomes such as number of promotions would have been beneficial, yet we were limited by the availability of research studies that met our selection criteria. Second, as can be seen in Tables 1 and 2, some correlations were based on a small number of studies $(k)$. As mentioned above, career satisfaction and hierarchical level attained was based on three studies, and the relationship between FWC and both salary and hierarchical level suffered from this same limitation. As such, the influence of a large study may have unduly influenced the sample weighting of correlations. As research in this topical area accumulates, replications would be helpful in understanding how the influence of small $k$ 's has affected our findings.

\section{Future Research}

We see several potentially fruitful avenues for future, related research. First, Hoobler and colleagues' (2009) research found that managers perceived women as higher in FWC than men, and that this "family-work conflict bias" meant deleterious career outcomes (fewer promotions, lower perceptions of future promotability). Because gender seems to have a significant influence on managers' perceptions of whether their subordinates' work and family lives conflict, gender should be explored in future studies. If enough studies existed of all-male and all-female respondents, our model could be explored via a SEM two-group comparison to see if the effects of WFC/FWC on career varies by gender. Or, as in Byron (2005), another technique would be to test for whether the percentage of female respondents in the $k$ samples moderates the effects of WFC/FWC on career. 
Another idea for future research comes from several significant Q statistic results from Table 1. Specifically, Q was significant for the relationships between WFC and manager-rated work performance $\left(\mathrm{Q}_{\mathrm{w}}=350.80, p<.001, k=6\right)$, salary $\left(\mathrm{Q}_{\mathrm{b}}=19.59, p<\right.$ $.01, k=6)$, and career satisfaction $\left(\mathrm{Q}_{\mathrm{b}}=52.95, p<.001, k=6\right)$. $\mathrm{Q}$ was also significant for the relationships between FWC and manager-rated work performance $\left(\mathrm{Q}_{\mathrm{w}}=350.24, p<\right.$ $.001, k=7)$, self-reported work performance $\left(\mathrm{Q}_{\mathrm{w}}=16.46, p<.001, k=3\right)$, and career satisfaction $\left(\mathrm{Q}_{\mathrm{b}}=16.75, p<.001, k=3\right)$. A significant $\mathrm{Q}_{\mathrm{w}}$ indicates that all studies could not be adequately described within a single effect size and potential moderators might exist to explain the variability across studies (Lipsey \& Wilson, 2001). Because there were relatively few studies on which the correlations for the above relationships were based, we are unable to detect potential moderators of these relationships based on existing studies. So, as research accumulates which tests these same variables, an interesting next step for researchers will be to explore the boundary conditions of our model of the impact of WFC and FWC on these career outcomes.

Last, as Eby and scholars (2005) suggest, 1) the work and family literature lacks a richness of understanding regarding the specific situations that moderate the relationship between conflict and outcomes. Studies should continue to predict and describe the conditions that attenuate and/or strengthen the effects of conflict on career. Here is where our model of direct and meditational relationships falls short. For example, does type of family responsibility matter in workers' harsh judgments of their own performance? It might be that society's expectations for the hours parents spend with young children mean that when work conflicts with family, for parents with small children, they judge themselves even more harshly, and rate their work performance even lower. Perhaps the 
effects are not as strong for workers who care for a sick spouse or other family member. Eby and colleagues also suggest that 2) the work and family literature should place more of an emphasis on family variables--that scholars have been too focused on work outcomes. Our model confirms this bias toward the work realm in its focus on career outcomes. We agree that next steps would be to investigate what the accumulated research (through metaanalysis) tells us about the combined effects of WFC and FWC on non-work variables (beyond satisfaction - which has been addressed with greater frequency, c.f., Eby et al., 2005; Ford et al., 2007; Kossek \& Ozeki, 1998), such as marriage or relationship tenure and mental health.

\section{Theoretical Implications}

Our results enhance our theoretical understanding of the implications of intersections between work and family. While we called on the most commonly-used theory in the work and family literature, Conservation of Resources (van Steenbergen et al., 2007), we also applied a less common theory—self verification theory. We contended, as have others, that the threat of or actual loss of resources when the work and family domain are out of balance affects energy and effort (Campbell, 1990). We underscored this theoretical relationship with meta-analytic evidence that both types of conflict were associated with lower managerial work performance ratings, and that FWC was associated with lower salary. Also supporting the scarcity or COR theories, we found that, across research studies, workers who perceived WFC and FWC were seemingly left with less time and human energy, which was reflected attitudinally, in their lower career satisfaction. Perhaps our main theoretical contribution lies in testing the applicability of selfverification theory to outcomes of work and family conflict. We contended that today's 
expectations of the "ideal worker" and the "ideal parent/caregiver" are incompatible given limited time and energy, as in the Williams quote at the beginning of this manuscript. As such, self-verification theory was instrumental in explaining that when workers experience conflict, they will judge their own work performance harshly. Given these results, we advocate, as others have (Parker \& Hall, 1992; Eby et al., 2005), that, theoretically, the self is an important filter for understanding the outcomes of the work and family balancing act. Implications for Practice

According to the Families and Work Institute's study of United States employers, $92 \%$ of organizations offer at least eight work/life balance initiatives. As specific examples, $56 \%$ of employers offer paid leave for female employees who give birth and $11 \%$ of large employers provide direct financial support for eldercare programs (Galinsky, Bond, Sakai, Kim, \& Giuntoli, 2008). Employers are spending millions of dollars on family-friendly benefits each year. Thirty-seven percent report that this is a retention measure for valuable employees, and 18\% report a genuine interest in helping employees balance work and family (Galinsky et al., 2008). Yet, research has provided little conclusive evidence that this investment in family-friendly programs has helped ease WFC or FWC (Kelly et al., 2008), and the design of many work-life initiatives does not consider their impact on users' careers (Lobel \& Kossek, 1996). By extension, our study may suggest to organizations that family-friendly benefits are not the answer; what is more effective in improving employees' balance between work and family (and by extension improving their career outcomes) is improving certain aspects of the psychosocial work environment (Kelly et al., 2008). As we argued early in this paper, psychosocial norms regarding work and family expectations are a key factor determining the standards to which 
individuals hold themselves, and the outcomes that result under conditions of imbalance. Kelly and colleagues (2008) find consistent evidence that the psychosocial factors of supportive organizational cultures, perceived support from supervisors, and employees' sense of organizational flexibility over the time and timing of their work, do reduce individuals' perceptions of conflict. That is, employees' perceptions of the pressures, requirements, and support available in the work environment are more important than the amount of family-friendly initiatives an employer provides when it comes to resolving imbalance (Kelly et al., 2008). Our study underscores the salience of psychosocial work factors not just in relieving employees' sense of work and family imbalance, but in improving the career outcomes of imbalance. In organizational cultures where workers are not expected to be available "any time, anywhere," and family time is really non-work time, workers who have family responsibilities should be less harsh in their self-evaluations of work performance, and managers' work performance evaluations should be less negative as well. Further implications from our study would be that in supportive cultures, direct relationships between WFC/FWC and indicators of career success, both objective and attitudinal, should be less strong as well. Simply put, in cultures where it is okay to have family responsibilities, then career outcomes for those employees should improve (see Kelly et al., 2008 for suggested changes in organizational policies, practices, and benefits). In conclusion, our model of the glass-ceiling career effects of WFC and FWC suggests that psychosocial norms of the "ideal worker" as one who is unencumbered by family responsibilities may be in operation. Those who put work first seem to be rewarded. If the glass ceiling is defined quite narrowly and literally to mean movement up the corporate ladder, then we have not uncovered a glass ceiling effect, that is, both WFC and 
FWC were positively related to hierarchical level attained. But, if you use a broader definition that includes many markers of career progress (work performance assessments, salary, and career satisfaction) - then yes, workers who experience conflict between the work and family domains seem to suffer negative career implications. 


\section{References}

Acker, J. (1990). Hierarchies, jobs, bodies: A theory of gendered organizations. Gender \& Society, 4, 139-158.

Acker, J. (1992). From sex roles to gendered institutions. Contemporary Sociology, 21, 565-569.

Bond, J. T., Galinsky, E., \& Swanberg, J. E. (1998). The 1997 national study of the changing workforce. New York: Families and Work Institute.

Burke, R. J. (2001). Workaholism components, job satisfaction, and career progress. Journal of Applied Social Psychology, 31, 2339-2356.

Burke, R. J., \& Greenglass, E. R. (1999). Work-family conflict, spouse support, and nursing staff well-being during organizational restructuring. Journal of Occupational Health Psychology, 4, 327-336.

Byron, K. (2005). A meta-analytic review of work-family conflict and its antecedents. Journal of Vocational Behavior, 67, 169-198.

Cadsby, C.B., Song, F., \& Tapon, F. (2007). Sorting and incentive effects of pay for performance: An experimental investigation. Academy of Management Journal, 50, $387-405$.

Campbell, J. P. (1990). Modeling the performance prediction problem in industrial and organizational psychology. In M. D. Dunnette \& L. M. Hough (Eds.), Handbook of industrial and organizational psychology: Vol. 1 (2nd ed., pp. 687-732). Palo Alto, CA: Consulting Psychologists Press. 
Colquitt, J. A., Scott, B. A., \& LePine, J. A. (2007). Trust, trustworthiness, and trust propensity: A meta-analytic test of their unique relationships with risk taking and job performance. Journal of Applied Psychology, 92, 909-927.

Cortina, J. M., Chen, G., \& Dunlap, W. P. (2001). Testing interaction effects in LISREL: Examination and illustration of available procedures. Organizational Research Methods, 4, 324-360.

Crooker, K. J., Smith, F. L., \& Tabak, F. (2002). Creating work-life balance: A model of pluralism across life domains. Human Resource Development Review, 1, 387-419.

Dulac, T., Coyle-Shapiro, J. A-M, Henderson, D. J., \& Wayne, S. J. (2008). Not all responses to breach are the same: A longitudinal study examining the interconnectioin of social exchange and psychological contract processes in organizations. Academy of Management Journal, 51, 1079-1098.

Eby, L. T., Casper, W.J., Lockwood, A., Bordeaux, C., \& Brinley, A. (2005). Work and family research in IO/OB: Content analysis and review of the literature (19802002). Journal of Vocational Behavior, 66, 124-197.

Epley, N., \& Dunning, D. (2000). Feeling "Holier than thou": Are self-serving assessments produced by errors in self- or social prediction? Journal of Personality and Social Psychology, 79, 861-875.

Ezzedeen S. R., \& Swiercz, P. M. (2007). Development and initial validation of a cognitive-based work-nonwork conflict scale. Psychological Reports, 100, 979-999.

Fernandez, M. (1998). Asian Indian Americans in the Bay Area and the glass ceiling. Sociological Perspectives, 41,119-149. 
Foley, S., Kidder, D. L., \& Powell, G. N. (2002). The perceived glass ceiling and justice perceptions: An investigation of Hispanic law associates. Journal of Management, 28, 471-496.

Ford, M. T., Heinen, B. A., \& Langkamer, K. L. (2007). Work and family satisfaction and conflict: A meta-analysis of cross-domain relations. Journal of Applied Psychology, 92, 57-80.

Frone, M. R. (2000). Work-family conflict and employee psychiatric disorders: The National Comorbidity Study. Journal of Applied Psychology, 85, 888-895.

Frone, M. R., Russell, M., \& Cooper, M. L. (1997). Relation of work-family conflict to health outcomes: A four-year longitudinal study of employed parents. Journal of Occupational and Organizational Psychology, 70, 325-335.

Frye, K. N., \& Breaugh, J. A. (2004). Family-friendly policies, supervisor support, workfamily conflict, family-work conflict, and satisfaction: A test of a conceptual model. Journal of Business and Psychology, 19, 197-220.

Galinsky, E., Bond, J. T., Sakai, K., Kim, S. S., \& Giuntoli, N. (2008). 2008 national study of employers. New York, NY: Families and Work Institute.

Gilboa, S., Shirom, A., Fried, Y., \& Cooper, C. (2008). A meta-analysis of work demand stressors and job performance: Examining main and moderating effects. Personnel Psychology, 61, 227-271.

Goerke, M., Moller, J., Schulz-Hardt, S., Napiersky, U., \& Frey, D. (2004). 'It's not my fault-but only I can change it:” Counterfactual and prefactual thoughts of managers. Journal of Applied Psychology, 89, 279-292. 
Goldberg, C. B., Finkelstein, L. M., Perry, E. L, \& Konrad, A. M. (2004). Job and industry fit: The effects of age and gender matches on career progress outcomes. Journal of Organizational Behavior, 25, 807-829.

Grandey, A. A., \& Cropanzano, R. (1999). The conservation of resources model applied to work-family conflict and strain. Journal of Vocational Behavior, 54, 350-370.

Greenhaus, J. H., \& Beutell, N. (1985). Sources of conflict between work and family roles. Academy of Management Review, 10, 76-88.

Greenhaus, J. H., Parasuraman, S., \& Collins, K. M. (2001). Career involvement and family involvement as moderators of relationships between work-family conflict and withdrawal from a professional. Journal of Occupational Health Psychology, 6, 91-100.

Hammer, T. H., Saksvik, P. Ø., Nytrø, K., Torvatn, H., \& Bayazit, M. (2004). Expanding the psychosocial work environment: Workplace norms and work-family conflict as correlates of stress and health. Journal of Occupational Health Psychology, 9, 8397.

Heidemeier, H., \& Moser, K. (2009). Self-other agreement in job performance ratings: A meta-analytic test of a process model. Journal of Applied Psychology, 94, 353-370.

Hobfoll, S. E. (1989). Conservation of resources: A new attempt at conceptualizing stress. American Psychologist, 44, 513-524.

Hobfoll, S. E. (2001). The influence of culture, community, and the nested-self in the stress process: Advancing conservation of resources theory. Applied Psychology, 50, 337421. 
Hoobler, J. M., Wayne, S. J., \& Lemmon, G. (2009). Bosses’ perceptions of family-work conflict and women's promotability: Glass ceiling effects. Academy of Management Journal, 5, 939-957.

Hu, L., \& Bentler, P. M. (1999). Cutoff criteria for fit indexes in covariance structure analysis: Conventional criteria versus new alternatives. Structural Equation Modeling, 6, 1-55.

Hunter, J. E., \& Schmidt, F. L. (2004). Methods of meta-analysis: Correcting error and bias in research findings. Thousand Oaks, CA: Sage.

Hymowitz, C., \& Schellhardt, T. D. (1986). The glass ceiling. The Wall Street Journal: A Special Report, The Corporate Woman (March 24), D1, 4-5.

Joreskog, K. G., \& Sorbom, D. (1993). LISREL 8: User's reference guide. Chicago: Scientific Software International.

Karatepe, O. M., \& Kilic, H. (2007). Relationships with supervisor support and conflicts in the work-family interface with selected job outcomes of frontline employees. Tourism Management, 28, 238-252.

Kelly, E. L., Kossek, E. E., Hammer, L. B., Durham, M., Bray, J., Chermack, K., Murphy, L. A., \& Kaskubar, D. (2008). Getting there from here: Research on the effects of work-family initiatives on work-family conflict and business outcomes. The Academy of Management Annals, 2, 305-349.

Kossek, E. E., \& Lambert, S. J. (2005). Work and life integration. Organizational, cultural, and individual perspectives. Mahwah, NJ: Lawrence Erlbaum Associates. 
Kossek, E. E., \& Ozeki, C. (1998). Work-family conflict, policies, and the job-life satisfaction relationship: A review and directions for organizational behaviorhuman resources research. Journal of Applied Psychology, 83, 139-149.

Kossek, E. E., \& Ozeki, C. (1999). Bridging the work-family policy and productivity gap: A literature review. Community, Work \& Family, 2, 7-32.

Lipsey, M., \& Wilson, D. (2001). Practical meta-analysis. Thousand Oaks, CA: Sage.

Lobel, S., \& Kossek, E. E. (1996). Human resource strategies to support diversity in work and personal lifestyles: Beyond the 'family-friendly' organization. In Kossek, E.E., \& Lobel, S. (Eds.), Managing diversity: Human resource strategies for transforming the workplace (pp. 221-244). Cambridge, MA: Blackwell Publishers.

Marks, S. R. (1977). Multiple roles and role strain: Some notes on human energy, time, and commitment. American Sociological Review, 42, 921-936.

Martins, L. L., Eddleston, K. A., \& Veiga, J. F. (2002). Moderators of the relationship between work-family conflict and career satisfaction. Academy of Management Journal, 45, 399-409.

McEvoy, G. M., \& Cascio, W. F. (1989). Cumulative evidence of the relationship between employee age and job performance. Journal of Applied Psychology, 74, 11-17.

Michel, J. S., Mitchelson, J. K., Kotrba, L. M., LeBreton, J. M. \& Baltes, B. B. (2009). A comparative test of work-family conflict models and critical examination of workfamily linkages. Journal of Vocational Behavior, 74, 199-218.

Milliken, F. J., \& Dunn-Jensen, L. M. (2005). The changing time demands of managerial and professional work: Implications for managing the work-life boundary. In Kossek, E.E. \& Lambert, S.J. (Eds.), Work and life integration: Organizational, 
cultural, and individual perspectives (pp.43-59). Mahwah, NJ: Lawrence Erlbaum Associates.

Netemeyer, R. G. Boles, J. S. \& McMurrian, R. (1996). Development and validation of work-family conflict and family-work conflict scales. Journal of Applied Psychology, 81, 400-410.

Netemeyer, R. G., Maxham, J. G. III, \& Pullig, C. (2005). Conflicts in the work-family interface: Links to job stress, customer service employee performance, and customer purchase intent. Journal of Marketing, 69, 130-143.

Ng, T. W. H., Eby, L. T., \& Sorensen, K. L. (2005). Predictors of objective and subjective career success: A meta-analysis. Personnel Psychology, 58, 367-408.

Ng, T. W. H., \& Feldman, D. C. (2008). Long work hours: a social identity perspective on meta-analysis data. Journal of Organizational Behavior, 29, 853-880.

Parasuraman, S., \& Simmers, C. A. (2001). Type of employment, work-family conflict and well-being: A comparative study. Journal of Organizational Behavior, 22, 551568.

Parker, V. A., \& Hall, D.T. (1992). Conclusion: Expanding the domain of family and work issues. In S. Zedeck (Ed.), Work, families, and organizations. San Francisco, CA: Jossey Bass.

Peluchette, J. V. E. (1993). Subjective career success: The influence of individual difference, family, and organizational variables. Journal of Vocational Behavior, 43, 198-208.

Quick, J. D., Henley, A. B., \& Quick, A. C. (2004). The balancing act—at work and at home. Organizational Dynamics, 33, 426-438. 
Ragins, B. R., \& Cotton, J. L. (1991). Easier said than done: Gender differences in perceived barriers to gaining a mentor. Academy of Management Journal, 34, 939951.

Seibert, S. E., Kraimer, M. L., \& Liden, R. C. (2001). A social capital theory of career success. Academy of Management Journal, 44, 219-237.

Smith, H. (2001). “Juggling work and family.” PBS.

Sobel, M. E. (1982). Asymptotic Confidence Intervals for Indirect Effects in Structural Equation Models. Sociological Methodology, 13, 290-312.

Swann, W. B., Jr. (1987). Identity negotiation: Where two roads meet. Journal of Personality and Social Psychology, 53, 1038-1051.

Swann, W. B., Jr., Griffin, J. J., Jr., Predmore, S. C., \& Gaines, B. (1987). Cognitiveaffective crossfire: When self-consistency meets self-enhancement. Journal of Personality and Social Psychology, 52, 881-889.

Swann, W. B., Jr., Pelham, B.W., Krull, D. S. (1987). Agreeable fancy or disagreeable truth? Reconciling self-enhancement and self-verification. Journal of Personality and Social Psychology, 57, 782-791.

Thatcher, S. M. B., \& Zhu, X. (2006). Changing identities in a changing workplace: Identification, identity enactment, self-verification, and telecommuting. Academy of Management Review, 31, 1076-1088.

Van Steenbergen, E. F., Ellemers, N., \& Mooijaart, A. (2007). How work and family can facilitate each other: Distinct types of work-family facilitation and outcomes for women and men. Journal of Occupational Health Psychology, 12, 279-300. 
Viswesvaran, C., \& Ones, D. S. (1995). Theory testing: Combining psychometric metaanalysis and structural equations modeling. Personnel Psychology, 48, 865-885.

Viswesvaran, C., Ones, D. S., \& Schmidt, F. L. (1996). Comparative analysis of the reliability of job performance ratings. Journal of Applied Psychology, 81, 557-574.

Wayne, S. J., Liden, R. C., Kraimer, M. L., \& Graf, I. K. (1999). The role of human capital, motivation, and supervisor sponsorship to career success. Journal of Organizational Behavior, 20, 577-595.

Williams, L. J., Bozdogan, H., \& Aiman-Smith, L. (1996). Inference problems with equivalent models. In G. A. Marcoulides \& R. E. Schumacker (Eds.), Advanced Structural Equation Modeling: Issues and Techniques (pp.279-314). Mahwah, NJ: Erlbaum.

Witt, L. A., \& Carlson, D. S. (2006). The work-family interface and job performance: Moderating effects of conscientiousness and perceived organizational support. Journal of Occupational Health Psychology, 11, 343-357.

Zhao, H., Wayne, S. J., Glibkowski, B. C., \& Bravo, J. (2007). The impact of psychological contract breach on work-related outcomes: A meta-analysis. Personnel Psychology, 60, 647-680. 
Table 1

Meta-Analysis Results of the Relationship between WFC and FWC and Career-Related Outcomes

\begin{tabular}{|c|c|c|c|c|c|c|c|c|c|c|}
\hline \multirow[t]{2}{*}{ The Relationship between } & \multirow[t]{2}{*}{$\mathrm{k}$} & \multirow[t]{2}{*}{$\mathrm{N}$} & \multirow[t]{2}{*}{$\gamma$} & \multirow[t]{2}{*}{$\rho$} & \multirow[t]{2}{*}{$\mathrm{SD} \rho$} & \multirow[t]{2}{*}{$95 \% \mathrm{CI}$} & \multirow[t]{2}{*}{$80 \% \mathrm{CV}$} & \multirow[t]{2}{*}{ Fail-safe k } & \multicolumn{2}{|c|}{ Homogeneity tests } \\
\hline & & & & & & & & & $\mathrm{Q}_{\mathrm{b}}$ & $\mathrm{Q}_{\mathrm{w}}$ \\
\hline \multicolumn{11}{|l|}{ WFC and $\ldots$} \\
\hline Performance & 11 & 2169 & -.10 & -.17 & .14 & $-.25,-.09$ & $-.35,-.01$ & 107 & $44.78 * * *$ & \\
\hline Manager-rated performance & 6 & 1120 & -.16 & -.19 & .19 & $-.34,-.04$ & $.26, .74$ & 61 & & $350.80 * * *$ \\
\hline Self-reported performance & 5 & 1038 & -.02 & -.03 & .15 & $-.16,-.01$ & $.31, .69$ & 34 & & 5.01 \\
\hline Salary & 6 & 2719 & .11 & .13 & .07 & $.05, .17$ & $.13, .57$ & 61 & $19.59 * *$ & \\
\hline Hierarchical level attained & 4 & 2945 & .11 & .13 & .07 & $.04, .18$ & $.17, .87$ & 40 & $10.88^{*}$ & \\
\hline Career satisfaction & 6 & 1859 & -.09 & -.11 & .13 & $-.21,-.01$ & $.33, .67$ & 60 & $52.95 * * *$ & \\
\hline \multicolumn{11}{|l|}{ FWC and... } \\
\hline Performance & 10 & 1882 & -.15 & -.18 & .18 & $-.29,-.07$ & $-.40,-.05$ & 133 & $39.74 * * *$ & \\
\hline Manager-rated performance & 7 & 1305 & -.12 & -.16 & .13 & $-.26,-.06$ & $.33, .67$ & 86 & & $350.24 * * *$ \\
\hline Self-reported performance & 3 & 577 & -.19 & -.22 & .18 & $-.42,-.02$ & $.27, .73$ & 16 & & $16.46^{* * *}$ \\
\hline Salary & 3 & 1814 & -.07 & -.08 & .03 & $-.10, .-.04$ & $.36,1.08$ & 30 & 4.12 & \\
\hline Hierarchical level attained & 3 & 1970 & .10 & .11 & .03 & $.07, .13$ & $.38, .95$ & 43 & 3.10 & \\
\hline Career satisfaction & 3 & 470 & -.17 & -.22 & .01 & $-.23, .-21$ & $.49, .51$ & 52 & $16.75 * * *$ & \\
\hline
\end{tabular}

Note. WFC=Work-family conflict; FWC=Family-work conflict, $\mathrm{k}=$ number of studies, $\mathrm{N}=$ cumulative sample size, $\quad \gamma=$ uncorrected meta-analytic correlation; $\rho=$ corrected meta-analytic correlation; $\mathrm{SD} \rho=$ standard deviation of corrected meta-analytic correlation; $\mathrm{CI}=$ confidence interval; $\mathrm{CV}=$ credibility interval.

$* p<.05, * * p<.01, * * * p<.001$. 
Table 2

Meta-analytic Correlation Matrix

\begin{tabular}{|c|c|c|c|c|c|c|c|}
\hline & 1 & 2 & 3 & 4 & 5 & 6 & 7 \\
\hline \multicolumn{8}{|l|}{ 1. WFC } \\
\hline $\mathrm{k}$ studies & -- & & & & & & \\
\hline $\mathrm{N}$ total observations & -- & & & & & & \\
\hline 2. FWC & .53 & & & & & & \\
\hline k studies & 56 & & & & & & \\
\hline $\mathrm{N}$ total observations & 18,948 & & & & & & \\
\hline 3. Career satisfaction & -.13 & -.20 & & & & & \\
\hline k studies & 6 & 3 & & & & & \\
\hline $\mathrm{N}$ total observations & 1,859 & 470 & & & & & \\
\hline 4. Salary & .13 & -.08 & $.28^{\mathrm{b}}$ & & & & \\
\hline $\mathrm{k}$ studies & 6 & 3 & 8 & & & & \\
\hline $\mathrm{N}$ total observations & 2,719 & 1,814 & 1,845 & & & & \\
\hline 5. Hierarchical level attained & .13 & .11 & $-.13^{\mathrm{a}}$ & $.13^{\mathrm{a}}$ & & & \\
\hline k studies & 4 & 3 & 3 & 6 & & & \\
\hline $\mathrm{N}$ total observations & 2,945 & 1,970 & 1,308 & 14,278 & & & \\
\hline 6. Performance & -.13 & -.19 & $.14^{\mathrm{b}}$ & $.27^{\mathrm{b}}$ & $.28^{\mathrm{a}}$ & & \\
\hline k studies & 10 & 10 & 3 & 9 & 5 & & \\
\hline $\mathrm{N}$ total observations & 2,022 & 1,882 & 1,358 & 7,350 & 12,496 & & \\
\hline 7. Age & $-.05^{\mathrm{a}}$ & $-.10^{\mathrm{a}}$ & $0^{\mathrm{c}}$ & $.26^{\mathrm{c}}$ & $.17^{\mathrm{a}}$ & $.06^{\mathrm{d}}$ & \\
\hline $\mathrm{k}$ studies & 19 & 13 & 26 & 52 & 7 & 96 & \\
\hline $\mathrm{N}$ total observations & 6,144 & 4,642 & 11,913 & 40,197 & 3,883 & 38,983 & \\
\hline
\end{tabular}

Note. All values are from our meta-analysis unless otherwise noted.

$\mathrm{a}=$ from a separate meta-analysis we conducted for the purpose of our SEM.

$\mathrm{b}=$ from Kammeyer-Mueller and Judge (2008).

$\mathrm{c}=$ from $\mathrm{Ng}$, Eby, and Sorensen (2005).

$\mathrm{d}=$ from McEvoy and Cascio (1989). 
TABLE 3

Results of Model Comparisons

\begin{tabular}{|c|c|c|c|c|c|c|c|}
\hline Model & $\chi^{2}$ & $d f$ & GFI & NFI & CFI & RMSEA & SRMR \\
\hline \multicolumn{8}{|l|}{ Hypothesized Partial } \\
\hline Mediation Model & 18.80 & 4 & 0.99 & 0.99 & 0.99 & 0.05 & 0.01 \\
\hline Structural Null Model & 2126.52 & 21 & 0.81 & 0.10 & 0.10 & 0.42 & 0.17 \\
\hline Model $1^{\mathrm{a}}$ & 182.99 & 8 & 0.94 & 0.91 & 0.91 & 0.10 & 0.04 \\
\hline Model $2^{\mathrm{b}}$ & 546.14 & 10 & 0.91 & 0.70 & 0.70 & 0.16 & 0.10 \\
\hline Model $3^{c}$ & 731.73 & 9 & 0.85 & 0.65 & 0.65 & 0.19 & 0.10 \\
\hline Model $4^{\mathrm{d}}$ & 801.69 & 11 & 0.92 & 0.61 & 0.61 & 0.18 & 0.11 \\
\hline
\end{tabular}

Note. $\mathrm{CFI}=$ comparative fit index, $\mathrm{NFI}=$ normed fit index, GFI $=$ goodness-of-fit index, RMSEA= rootmean-square error of approximation, and SRMR = standardized root-mean-square-residual.

The paths from age to salary and from age to hierarchical level attained were controlled in all models except the structural null model.

${ }^{a}$ In comparison to the hypothsized model, Model 1 is a direct-effects model with paths from WFC and FWC pointing to all the career-related outcomes.

${ }^{\mathrm{b}}$ Model 2 is a full mediation model with no paths from WFC and FWC to salary, hierarchical level, and career satisfaction.

${ }^{\mathrm{c}}$ Model 3 contains paths from WFC and FWC to salary and hierarchical level, salary and hierarchical level to performance, and performance to career satisfaction.

${ }^{\mathrm{d}}$ Model 4 involves paths from salary and hierarchical level to WFC and FWC, WFC and FWC to performance, and performance to career satisfaction.

Harmonic mean $N=2439$. 


\section{Figure Captions}

Figure 1. Hypothesized Model

Figure 2. Structural Path Estimates of the Hypothesized Model 


\section{Figure 1}

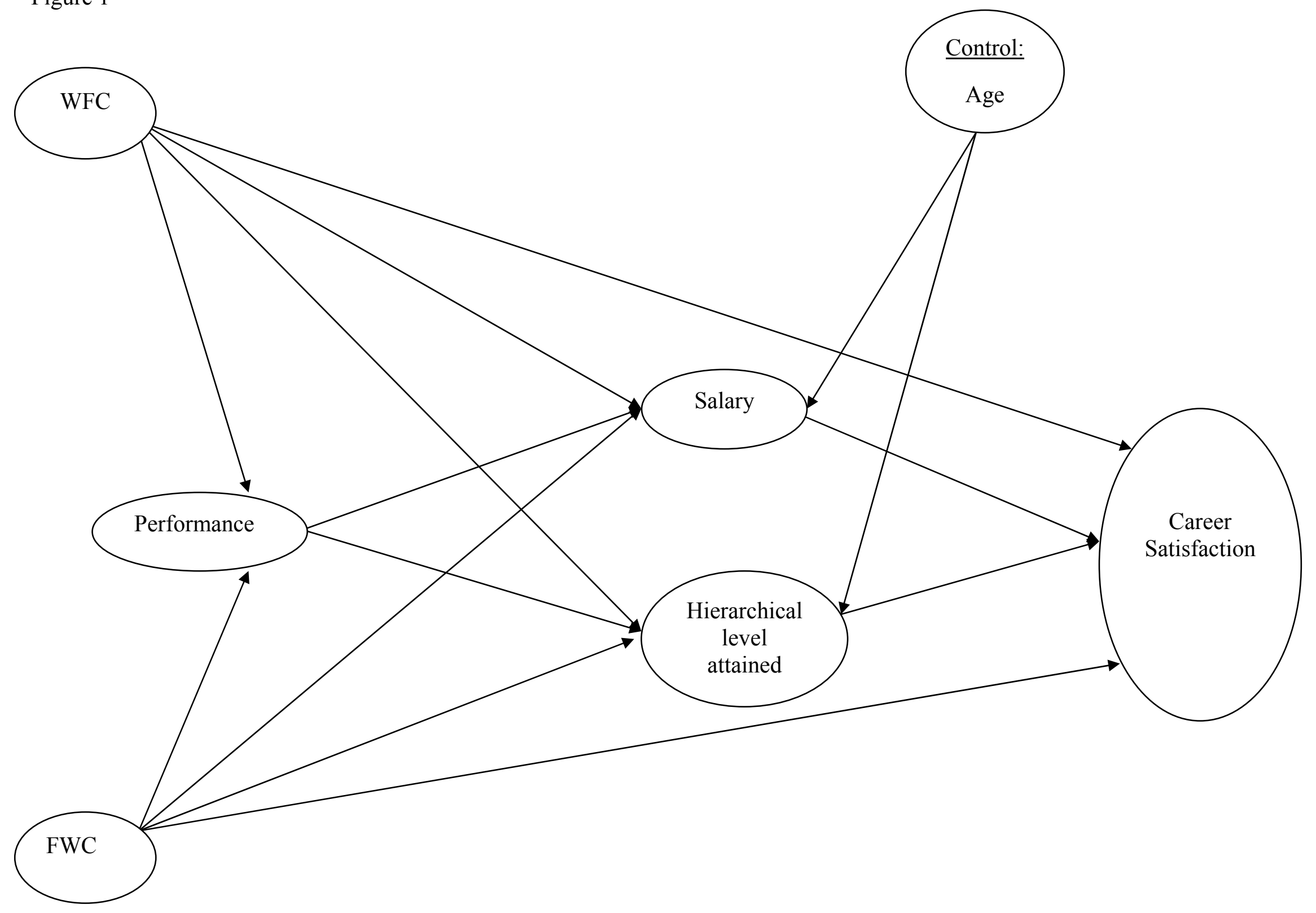


Figure 2

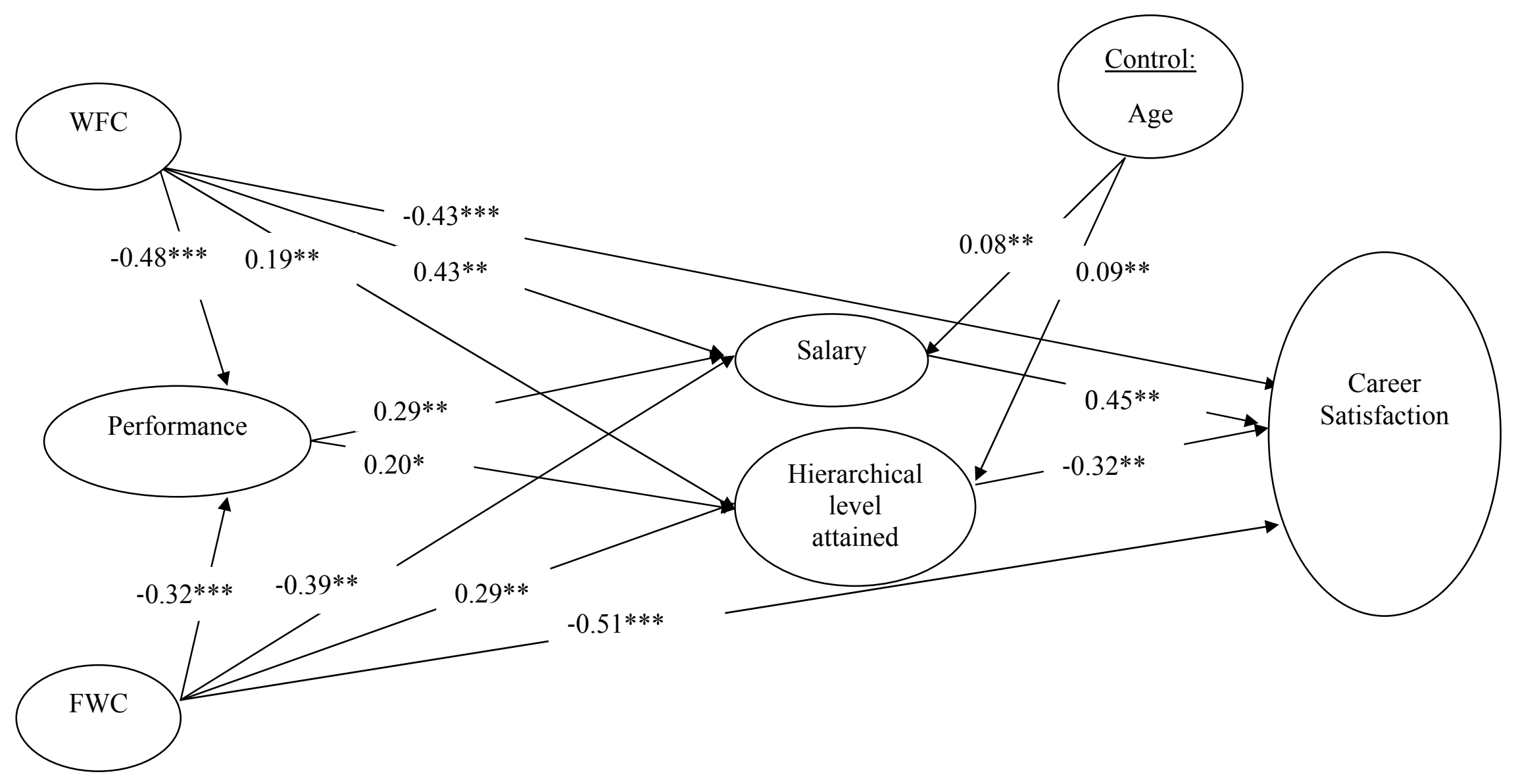

Note. ${ }^{\text {a }}$ standardized path estimates were reported.

$* p<.05, * * p<.01, * * * p<.001$. 